\title{
A distance-to-target weighting method for Europe 2020
}

\author{
Valentina Castellani $^{1} \cdot$ Lorenzo Benini $^{1} \cdot$ Serenella Sala $^{1} \cdot$ Rana Pant $^{1}$
}

Received: 11 August 2015 /Accepted: 24 February 2016/Published online: 22 March 2016

(C) The Author(s) 2016. This article is published with open access at Springerlink.com

\begin{abstract}
Purpose Distance-to-target (DTT) methods are weighting methods aimed at assessing the distance of an existing situation from a desired state (the target). Weighting factors in DTT methods could be based on calculation which is performed on normalization factors (NFs) developed for life cycle assessment (LCA). At present, some DTT weighting sets have been developed. However, there is no DTT weighting set assessing the distance of EU domestic impacts from the desired state set by EU binding or non-binding policy targets (e.g., those related to the "Climate and Energy Package" and the "Roadmap to a Resource Efficient Europe").

Methods In the present work, a methodology to derive target references from policy-based targets in 2020 (TRs2020), both binding (A) and non-binding (B), is presented. Resulting target factors and DTT weighting factors are then compared to the current normalisation factors (based on 2010 normalization references). The resulting weighting factor (WF) sets are presented and discussed in light of their use for decision support in policy and business contexts. We applied the WF sets to characterization results to an example (the EU energy mix process) aiming at illustrating key differences and effects on the results.
\end{abstract}

Responsible editor: Jeroen Guinée

Electronic supplementary material The online version of this article (doi:10.1007/s11367-016-1079-8) contains supplementary material, which is available to authorized users.

Serenella Sala

Serenella.sala@jrc.ec.europa.eu

1 European Commission, Joint Research Centre, Institute for Environment and Sustainability, Sustainability Assessment Unit, Via Enrico Fermi 2749; T.P. 270, 21027 Ispra, VA, Italy
Results and discussion The three reference sets (NRs2010, TRs2020A, and TRs2020B) show, in some impact categories, a relatively small difference. WFs referred to set A and set B result to be quite similar, with the only exception of water depletion impact category, for which a very relevant change is foreseen when considering the effect of the non-binding target of limiting the abstraction of water resource to $20 \%$ of the available renewable water resources. This is mainly due to the higher difficulty in deriving quantitative targets from non-binding strategies and policies rather than from binding ones.

Conclusions The resulting weighting sets present strengths and limitations. The translation of policy targets into quantitative modifications to the baseline inventories appeared to be not a straightforward task, due to several reasons discussed in the paper (e.g., not all the policy targets are expressed in quantitative terms or can be translated into quantitative reductions and modifications of the elementary flows in the existing baseline inventories). Aiming at improving the effectiveness in supporting policies, further development of the methodology may be the integration with other DTT approaches such those based on carrying capacity, developed to integrate Earth's carrying capacity concept and planetary boundaries.

Keywords Distance to target - EU domestic impacts · EU policy targets $\cdot$ Normalization $\cdot$ Product environmental footprint $(\mathrm{PEF}) \cdot$ Weighting

\section{Introduction}

In the context of life cycle assessment (LCA), according to ISO 14044 (ISO 2006), normalization and weighting are optional steps of life cycle impact assessment 
(LCIA). Those steps allow the practitioner expressing results after characterization using a common reference impact and then aggregating the results into a single score, giving different weight to impacts. This supports the comparison between alternatives using reference numerical scores (Bengtsson and Steen 2000; Huppes et al. 2012). In the context of LCA in support to policy, normalization (i.e., the use of reference numerical scores) can help the following: (i) to identify the most relevant impact categories in a given region or for a given product, i.e., to define Product Category Rules (PCRs) (as in the case of Product Environmental Footprint (PEF) of products (EC 2013), and (ii) to address eco-innovation policies and strategies toward the most effective solutions for decoupling.

The normalization references express the total impact of a reference region for a certain impact category (e.g., climate change, eutrophication, etc.) in a reference year. Weighting reflects a process of giving different relative importance to impacts based upon a set of criteria (Finnveden et al. 2009).

According to ISO standards, weighting shall not be applied in the context of comparative assertions, especially because any weighting implies the use of value judgements and comes with the risk of increased in transparency. However, in practice, any time, there is a decision made, e.g. selecting between different products, a type of weighting is applied, be it explicit or implicit, be it conscious or involuntarily. When LCA is used in support of policies, weighting can help to summarize the results in a reduced number of impact categories or even a single score (Galatola and Pant 2014). Therefore, the development of a weighting set that is transparently presented and whose limitations are highlighted and discussed can help not only to lead to better decisions but also to make the decision process more transparent.

In LCA literature (Finnveden et al. 2002; Pennington et al. 2004; Huppes and van Oers 2011), three major groups of weighting methods could be identified: (i) monetization, which have a monetary measure involved in evaluation (Pizzol et al. 2015); (ii) panel-based (a group of methods where the relative importance of damages, impact categories, or interventions is derived from a group of people through surveys). This could be value based (Powell et al. 1997; Myllyviita et al. 2012, 2014) or preference based (Soares et al. 2006; Frischknecht et al. 2008 and Heijungs 2008); and (iii) distance to target (where characterization results are related to target levels, either policy based or based on carrying capacity).

Weighting factors in distance-to-target (DTT) weighting methods could be based on calculations that are performed on normalization factors. The weighting factor is defined for each environmental impact category as the ratio between the actual impact and the target impact. The target impacts can be the expected level of impact foreseen by policy targets or physical thresholds not to be trespassed as in the case of planetary boundaries.
Some examples of existing DTT weighting methods are as follows:

- Eco-scarcity v. 2013 (Frischknecht and Büsser Knöpfel 2013): eco-factors, expressed as eco-points $(E P=U B P)$ per unit of pollutant emission or resource extraction, are the key parameter used by the method. With this method, eco-factors are determined based on the current emission situation and the political targets set by Switzerland or by international policy and supported by Switzerland. The method was first published in 1990.

- EDIP 1997 (Wenzel et al. 1997; Hauschild and Wenzel 1998): weighting is based on a DTT approach using political reduction targets (only binding targets) for environmental impacts and working environment impacts and supply horizon for resources. The weighted environmental impact potential (WEP) is expressed in the unit "target person-equivalent," i.e., as parts of that person-equivalent which corresponds to the chosen target impact in the weighting.

- Lin et al. (2005) and Wang et al. (2011): weighting factors based on environmental policy target for China.

- Tuomisto et al. (2012): set of weighting factors in which the weighting factor for each impact category is generated by calculating the ratio between the current position and the estimated safe boundary foreseen by Rockström et al. (2009).

- Bjørn and Hauschild (2015) propose to integrate carrying capacity in the normalization step of LCA through a new normalization reference applicable to impact scores at midpoint level. The normalization reference is expressed as the carrying capacity divided by the population in the reference region and thus described the annual personal share of environmental impact space available according to the carrying capacity.

Several examples exist about the calculation of normalization factors at the national scale, such as Dahlbo et al. (2013) for Finland, Guinée et al. (2002) for the Netherlands, Strauss et al. (2006) for South Africa (about mined abiotic resources), and Bare et al. (2006) for the USA. Wegener-Sleeswijk et al. (2008) developed normalization factors taking as reference the situation in EU and the whole world in 2000. However, there is no DTT weighting set assessing the distance of EU domestic impacts from the desired state set by EU binding and nonbinding targets for 2020 (e.g., the Climate and Energy Package, EC 2009, the Roadmap to a Resource Efficient Europe, EC 2011, etc.).

In the context of the current development of the Product Environmental Footprint (PEF), several 
weighting methods are under evaluation and DTT is one of the options considered. The present study is about the development of a DTT method for EU, based on recently released normalization factors (NFs) for 2010 for PEF (Benini et al. 2014a; Sala et al. 2015).

The aims of the study are:

- To develop DTT weighting factors (WFsA and WFsB) for the EU based on binding and non-binding policy targets.

- To compare different sets of weighting factors discussing the implications and the effects on final results.

The paper is organized as follows: after an introduction about normalization and DTT weighting methods, the methodological steps undertaken to develop NFs and WFs applying EU binding and non-binding targets for 2020 are presented. In the following sections, the resulting TFs2020A and TFs2020B sets are illustrated and compared to NFs2010, and finally, results of normalization and weighting factors as distance to the targets are discussed in light of their use in policy context and for products.

\section{Methodology}

The present paper illustrates the methodology applied to develop the 2020 target references - applying Europe 2020 policy targets - and to derive relative DTT weighting factors.

In DTT weighting methods, the weight assigned to each impact category is the ratio between the normalization reference value (or NF) and the target value (Eq. (1)) (Finnveden et al. 2002; Pennington et al. 2004; Seppälä and Hämäläinen 2001)

$w_{i}=\frac{N_{i}}{T_{i}}$

where

$w_{i} \quad$ Weight of the $i$ th impact category

$N_{i} \quad$ Normalization reference for the $i$ th impact category

$T_{i} \quad$ Target reference for the $i$ th impact category

Some DTT methods magnify the distance to the selected target putting a power factor into the formula (e.g., Frischknecht and Büsser Knöpfel 2013). The underlying concept of the method is the same as in Eq. (1), i.e., giving more weight to those impacts which are the farthest from the target, but the results can be spread on a wider range of values.

As reported in the equations below (Eq. (2) to (5)), the application of a DTT weighting method to any LCA study changes the reference to which the impacts resulting from the LCIA phase are assessed against. As a result, when applying DTT methods, the set of normalization references $\left(N_{i}\right)$ is substituted with a set of target-based normalization references $\left(T_{i}\right)$ producing the respective normalized (and weighted) impacts $\left(N I_{i}\right.$ and $\left.T I_{i}\right)$. In the present study, the target-based normalization reference for each impact category is derived from EU policy targets for 2020. Therefore, normalization reference values are the NFs for the current environmental scenario (reflecting the status quo in 2010) and target reference values are derived from the application of policy targets for 2020 .

$$
\begin{aligned}
& I_{i}=\sum_{j=1}^{j=m} e_{j} \cdot c f_{i j} \\
& N I_{i}=\frac{\sum_{j=1}^{j=m} e_{j} \cdot c f_{i j}}{N_{i}} \\
& W N I_{i}=\frac{\sum_{j=1}^{j=m} e_{j} \cdot c f_{i j}}{N_{i}} \cdot w_{i}=\frac{\sum_{j=1}^{j=m} e_{j} \cdot c f_{i j}}{N_{i}} \cdot \frac{N_{i}}{T_{i}} \\
& W N I_{i}=T I_{i}=\frac{\sum_{j=1}^{j=m} e_{j} \cdot c f_{i j}}{T_{i}}
\end{aligned}
$$

where

$I_{i} \quad$ Impact of the $i$ th impact category for a given product or service

$e_{j} \quad i$ th elementary flow associated with a given product or service

$c f_{i j} \quad$ Characterization factor of the $j$ th elementary flow for the $i$ th impact category

$N_{i} \quad$ Normalization reference for the $i$ th impact category

$T_{i} \quad$ Target value for the $i$ th impact category

$N I_{i} \quad$ Normalized impact of the $i$ th impact category

$W N I_{i} \quad$ Weighted and normalized impact of the $i$ th impact category for a given product or service

$T I_{i} \quad$ Target-based normalized impact of the $i$ th impact category for a given product or service

In the present paper, we apply Eq. (1) to derive DTT weighting sets.

The target references are derived from the application of binding and non-binding targets to the existing inventory at 2010. It results in two sets of target-based normalization references (or target references, $\mathrm{T}$ in Eq. (1)), which reflect the expected state for 2020: TRs2020A (target values for each impact category derived from implementation of binding targets) and TRs2020B (target values for each impact category derived from implementation of from both binding and non-binding targets).

The method is specific for the International Life Cycle Data System (ILCD-specific); i.e., the weights calculated in the present study and presented in Table 1 should be 
Table 1 Normalization references for year 2010 (NRs2010) and target references for year 2020 (TRs2020A applying binding targets and TRs2020B applying binding and non-binding targets) and related weighting factors (WFsA and WFsB)

\begin{tabular}{llllll}
\hline & NRs2010 & TRs2020A & TRs2020B & WFsA & WFsB \\
\hline Climate change midpoint & $4.60 \mathrm{E}+12$ & $3.95 \mathrm{E}+12$ & $3.95 \mathrm{E}+12$ & 1.16 & 1.16 \\
Ozone depletion midpoint & $1.08 \mathrm{E}+07$ & $1.04 \mathrm{E}+07$ & $1.04 \mathrm{E}+07$ & 1.05 & 1.05 \\
Human toxicity midpoint, cancer effects & $1.88 \mathrm{E}+04$ & $1.68 \mathrm{E}+04$ & $1.68 \mathrm{E}+04$ & 1.12 & 1.12 \\
Human toxicity midpoint, non-cancer effects & $2.69 \mathrm{E}+05$ & $2.65 \mathrm{E}+05$ & $2.65 \mathrm{E}+05$ & 1.01 & 1.01 \\
Particulate matter/respiratory inorganics & $1.93 \mathrm{E}+09$ & $1.59 \mathrm{E}+09$ & $1.59 \mathrm{E}+09$ & 1.21 & 1.21 \\
$\quad$ midpoint & & & & & \\
Ionizing radiation midpoint, human health & $5.64 \mathrm{E}+11$ & $5.64 \mathrm{E}+11$ & $5.64 \mathrm{E}+11$ & 1.00 & 1.00 \\
Photochemical ozone formation midpoint, & $1.58 \mathrm{E}+10$ & $1.24 \mathrm{E}+10$ & $1.24 \mathrm{E}+10$ & 1.28 & 1.28 \\
$\quad$ human health & $2.36 \mathrm{E}+10$ & $2.00 \mathrm{E}+10$ & $2.00 \mathrm{E}+10$ & 1.18 & 1.18 \\
Acidification midpoint & $8.76 \mathrm{E}+10$ & $7.69 \mathrm{E}+10$ & $7.69 \mathrm{E}+10$ & 1.14 & 1.14 \\
Eutrophication terrestrial midpoint & $7.41 \mathrm{E}+08$ & $7.35 \mathrm{E}+08$ & $7.35 \mathrm{E}+08$ & 1.01 & 1.01 \\
Eutrophication freshwater midpoint & $8.44 \mathrm{E}+09$ & $7.45 \mathrm{E}+09$ & $7.45 \mathrm{E}+09$ & 1.13 & 1.13 \\
Eutrophication marine midpoint & $3.78 \mathrm{E}+13$ & $3.78 \mathrm{E}+13$ & $3.45 \mathrm{E}+13$ & 1.00 & 1.10 \\
Ecotoxicity freshwater midpoint & $4.46 \mathrm{E}+12$ & $4.24 \mathrm{E}+12$ & $3.86 \mathrm{E}+12$ & 1.05 & 1.15 \\
Land use midpoint & $4.06 \mathrm{E}+10$ & $4.06 \mathrm{E}+10$ & $6.36 \mathrm{E}+09$ & 1.00 & 6.38 \\
Resource depletion water, midpoint & $5.03 \mathrm{E}+07$ & $5.03 \mathrm{E}+07$ & $7.79 \mathrm{E}+07$ & 1.00 & 0.65 \\
Resource depletion, mineral, fossils, and & & & & & \\
$\quad$ renewable, midpoint & & & &
\end{tabular}

All the sets have been calculated applying ILCD 1.06 as LCIA method consistently used with the characterization factors used in the calculation of the normalization references.

The normalization references (NRs2010) used in this paper are those recommended by the European Commission-Joint Research Centre (EC-JRC) for the PEF (Benini et al. 2014a; Sala et al. 2015). The PEF NFs are based on an extensive inventory of emissions into air, water, and soil as well as resources extracted in EU which has been developed by EC-JRC (Sala et al. 2014), with the aim of calculating life-cycle-based indicators for resource efficiency (EC-JRC 2012a and 2012b; Benini et al. 2014b). The inventory, covering years from 1990 to 2010, is primarily based on extensive data collection at EU level, from different sources, as well as on extrapolation strategies and gap filling techniques for the calculation of missing flows. The PEF NFs take as reference the situation in EU-27 in 2010 by accounting for the impacts occurring within the domestic boundaries of EU and without including impacts associated with trade.

In the present paper, the methodology to derive target references from policy-based target in 2020 (TRs2020), both binding and non-binding, is presented. Resulting target factors (TFs2020 A and B) are then compared to the current normalisation factors (NFs2010) (based on 2010 normalization reference set).

The methodology implemented for calculating TFs2020 and related weighting factors (WFs) applies a DTT method based on binding and non-binding EU policy targets for 2020 . The methodological steps are as follows:

1. Identification of binding and non-binding EU targets for 2020.

2. Development of the target-based 2020 inventory. This is done through the application of the policy targets to the reference inventory (2010), so to simulate the reduction in emissions or resource extraction expected to occur in 2020 (e.g., reduction by $20 \%$ of GHG emissions in 2020 with reference to 1990). Those flows which are not targeted by any policy measure, binding or not binding, are not modified. This step leads to two new inventories for 2020: inventory A, in which only binding targets are applied, and inventory $\mathrm{B}$, on which both binding and non-binding targets are applied. From inventory A and inventory $\mathrm{B}$, applying ILCD mid-point characterization factors (EC-JRC 2011), two sets of target references are derived: TRs2020A and TRs2020B. Target factors (TFs2020A and TFs2020B) are the inverse of normalization references.

3. Calculation of two sets of WFs, WFsA and WFsB, respectively (according to Eq. (1)).

\subsection{Binding and non-binding EU targets for 2020}

The review of binding and non-binding targets has been made starting from EU policies as reported in Table S1. 
Binding targets are targets set by Directive or Regulations that imply an obligation for member states to reach the target before the foreseen deadline. Nonbinding targets are defined, for the purpose of the present study, as targets that are proposed in EU Communications not (yet) adopted, EU Strategies, supporting studies, etc., stating a future objective without posing a compulsory obligation to reach it before a fixed deadline or sanctions to be applied if the target is not reached.

The TFs 2020 presented in Sect. 3 is the result of step 2 (above), where each of the elementary flows is reduced from its baseline year (2010, 2005, or 1990), depending on the policy setting the target. Some targets related to the endpoint level are listed in Table S1 but could not be implemented in the calculation of the two updated NF set, because it was not possible to re-scale them at the midpoint or the inventory level (as explained in Sect. 4). The two target sets TFs2020A and TFs2020B are based on the following:

- TRs 2020 A: only binding targets in 2020

- TRs $2020 \mathrm{~B}$ : binding and non-binding targets in 2020

The methodological choices adopted are as follows:

- Re-scaling of the target to 2020 through linear interpolation when the policy target refers to a period in time beyond 2020 (e.g., some targets at 2030 have been used to linearly derive non-binding targets for 2020).

- When a target is set for the year 2020 and refers to a baseline other than2010, the target-based factor in 2020 has been calculated consistently with the related inventory year (e.g., GHGs' reductions at 2020 should be assessed compared to 1990; therefore, the $-20 \%$ has been applied to 1990 figures).

- Application at the level of elementary flows and proportional burden sharing. This implies that the reduction may simultaneously affect different impact categories (e.g., a reduction of NOx will imply reduction of NFs for acidification, photochemical ozone formation, etc.). In case that the target is set at the mid-point level and not at the flow level, the reduction burden is proportionally shared among all those substances contributing to the impact category, unless other policies have already imposed higher reduction targets on a specific substance. In that case, the highest target is adopted.

Further details about the binding and non-binding targets considered and the methodological assumptions made for each impact category are presented in SI (S1 and S2).

\section{Results and discussion}

The TRs2020A and TRs2020B are the results of step 2 of the methodology presented above, where each of the elementary flows is reduced from its baseline year (2010, 2005, or 1990), depending on the baseline year of the policy setting the target. The two target factor sets are TFs2020A (only binding targets in 2020) and TFs2020B (binding and non-binding targets in 2020). From these ones, the related WFs, WFsA and WFsB, were then calculated according to Eq. (1). Results are presented in Table 1.

The three reference sets (NRs2010, TRs2020A, and TRs2020B) show, in some impact categories, a relatively small difference. This could mean either that

- In some cases, the existing targets have only a limited effect on the inventory, resulting in slight modification of the normalization set and the related weighting.

- As explained more deeply in Sect. 4, the translation of binding and non-binding targets into modifications of the LCI flows is quite difficult because some of the targets set thresholds non-comparable with the structure of the inventory; therefore, the modifications do not take into account the whole range of possible improvements for expected status quo.

- As discussed in the Sect. 2, the equation applied for the calculation (Eq. (1)) does not magnify the distance between the current situation and the target, i.e., implicitly leads to a smaller range of results compared to DTT methods which are not based on linear distance from the targets.

In addition, it has to be noted that several binding targets refer to baseline year 2005. Hence, they have already affected the inventory 2010. Therefore, in some impact categories, there is only a small difference between NRs2010 and TRs2020 (A and B).

WFs referred to set A and set B result to be quite similar, with differences between the two ranging from $1 \%$ to about $30 \%$. The only exception is water depletion, for which a very relevant change is foreseen when considering the effect of the non-binding target of limiting the abstraction of water resource to $20 \%$ of the available renewable water resources and resources. The quite limited difference between the two sets is mainly due to the higher difficulty in deriving quantitative targets from non-binding strategies and policies rather than from binding ones. A future improvement of the methodology could aim at developing a way to translate also policy strategies into modifications of the underlying inventory flows.

Some of the results may be affected by the assumptions made in the implementation of the methodology and by the constraints posed by the original structure of the inventory. In the following paragraphs, the possible effects of these issues are discussed. 
Regarding water depletion, it has to be considered that, in the current inventory, abstraction includes all kinds of withdrawals (e.g., including cooling) but those for hydroelectricity generation. The average estimated ratio between consumption and abstraction is around $45 \%$, according to Vandecasteele et al. (2014). Therefore, if we had interpreted the target in a less stringent way by applying the threshold of $20 \%$ withdrawals to the available renewable resources only to consumptive uses (i.e., not accounting for water released to the water body after its use), the resulting NF2020B would have been $1.41 \mathrm{E}+$ $10 \mathrm{~m}^{3}$, with a resulting WF2020B of 2.88 .

It is also worthy to mention that the TRs2020B for the impact category Resource depletion, resulting from the application of binding and non-binding targets, is higher than the one deriving from the application of only binding targets. This is explained by the fact that the non-binding target about resource consumption reduction refers to the baseline year 2005, whereas the TR2020A refers to the inventory 2010. Since a significant reduction had already occurred from 2005 to 2010 at the domestic scale, the application of the target to 2005 inventory data does not lead to a reduction in the NF.

Moreover, the result of WFs for resources impact category may be highly influenced by the relative importance given to some elementary flows (e.g., some metals) to which a very high $\mathrm{CF}$ is assigned. Thus, even a small mass reduction of these flows leads to a significant reduction of the overall impact due to resource depletion (see Mancini et al. 2015). To quantify this effect, we decided to compare the WFs for resource depletion presented in Table S1 with the WFs that would be obtained if they were referred only to the effect of mass reduction at the inventory level instead of being referred to the impact variation at the midpoint level. Table S2.4 (Electronic Supplementary Material) presents the WFsB, either for each type of resources and for the overall category, deriving from the comparison of the mass amount in the inventories 2005, 2010, and 2020. When considering only the mass amount, the 2020 non-binding target results in a foreseen reduction of an additional $22 \%$ of the 2010 inventory.

In Fig. 1, the results of the characterization of the EU energy mix process (source: Ecoinvent database v. 2.2) are normalized using the three sets (NFs2010, TFs2020A, and TF2020B), to show an example of application to process-based LCA results. Normalization by TFs2020 A and B shows relevant differences from 2010 in human toxicity-cancer, freshwater ecotoxicty, and water depletion impact categories.

In Table 2, the WFs are compared to other weighting sets proposed in the literature, referred to either policy-based and carrying capacity targets (i.e., referred to physical thresholds as carrying capacity and planetary boundaries):

- WFs proposed by Hauschild and Potting (2003) and included in the EDIP 2003 LCIA method

- WFs by Tuomisto et al. (2012), based on the planetary boundary approach

- WFs as the ratio between ILCD NRs2010 and NRs based on carrying capacity thresholds by Bjorn and Hauschild (2015)

- WFs resulting from a previous work by Huppes and van Oers (2011) for EC-JRC: weighted average of three weighting sets at midpoint (EPA Science Advisory Board, BEES Stakeholder Panel, and NOGEPA, based on an interactive panel weighting exercise)

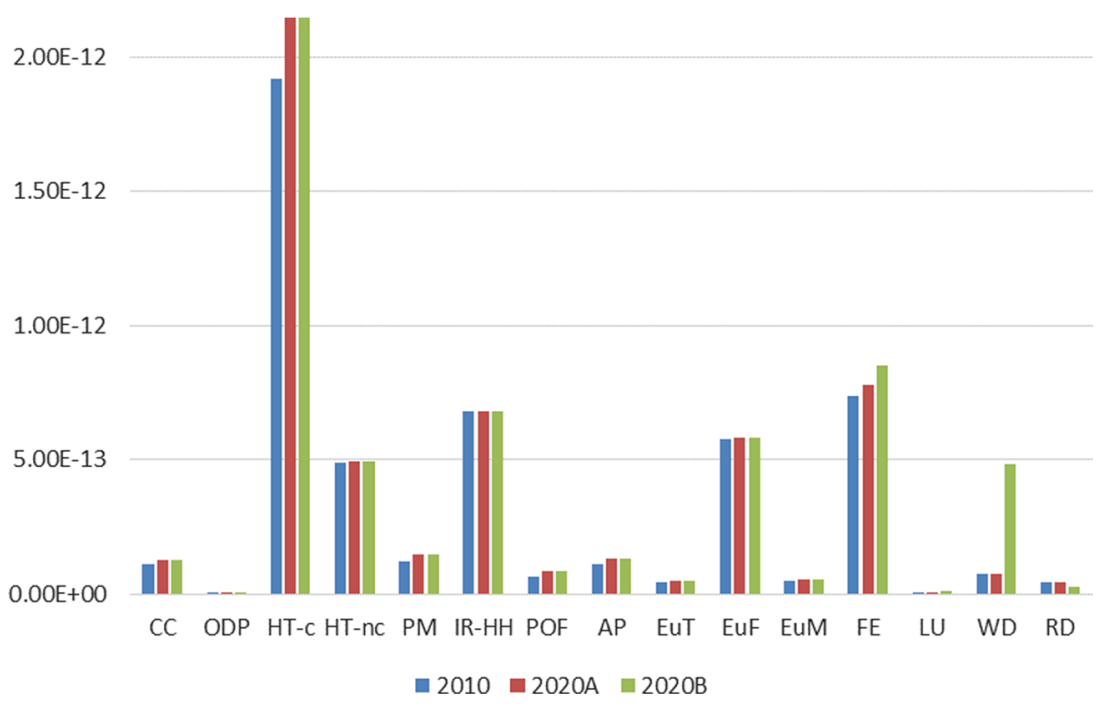

Fig. 1 Example of normalization applying the three sets of NFs. The NFs are applied to the characterization results (method: ILCD midpoint) of the process " $1 \mathrm{kWh}$ Electricity, medium voltage, production RER, at grid/RER U" from Ecoinvent v. 2.2 database. $C C$ climate change, $O D P$ ozone depletion potential, HT-c human toxicity-cancer, HT-nc human toxicity-non-cancer, $P M$ particulate matter, $I R-H H$ ionizing radiation, $P O F$ photochemical ozone formation, $A P$ acidification potential, EuT eutrophication, terrestrial, $E u F$ eutrophication, freshwater, $E u M$ eutrophication, marine, $F E$ freshwater ecotoxicity, $L U$ land use, $W D$ water depletion, $R D$ resources depletion 
Table 2 Comparison of the relative importance (in \%) of impact categories in the weighting factors resulting from the study, and in other sets of weighting factors proposed in the literature

\begin{tabular}{|c|c|c|c|c|c|c|}
\hline & WFsA (\%) & WFsB $(\%)$ & EDIP $2003(\%)$ & $\begin{array}{l}\text { Tuomisto et al. } \\
(2012)(\%)\end{array}$ & $\begin{array}{l}\text { Bjorn and Hauschild } \\
(2015)(\%)\end{array}$ & $\begin{array}{l}\text { Huppes and van } \\
\text { Oers (2011) (\%) }\end{array}$ \\
\hline Climate change & 7.1 & 5.4 & 1.5 & 10.4 & 36.1 & 23.2 \\
\hline Ozone depletion & 6.4 & 4.8 & 86.8 & 8.1 & 0.7 & 3.6 \\
\hline Human toxicity_cancer & 6.9 & 5.2 & 1.7 & n.a. & n.a. & 6.5 \\
\hline Human toxicity_non-cancer & 6.2 & 4.7 & 1.7 & n.a. & n.a. & 4.1 \\
\hline Particulate matter & 7.4 & 5.6 & n.a. & n.a. & n.a. & 6.6 \\
\hline Ionizing radiation $\mathrm{HH}$ & 6.1 & 4.6 & n.a. & n.a. & n.a. & 6.5 \\
\hline Photochemical ozone formation & 7.8 & 5.9 & 1.7 & n.a. & 34.2 & 5.4 \\
\hline Acidification & 7.2 & 5.5 & 1.8 & 8.4 & 1.4 & 4.2 \\
\hline Eutrophication terrestrial & 7.0 & 5.3 & 1.7 & 27.6 & 0.8 & n.a. \\
\hline Eutrophication freshwater & 6.2 & 4.7 & 1.4 & 6.5 & 8.5 & 7.0 \\
\hline Eutrophication marine & 6.9 & 5.2 & 1.9 & 27.6 & 1.4 & n.a. \\
\hline Land use & 6.1 & 5.1 & n.a. & 6.2 & 13.3 & 10.2 \\
\hline Ecotoxicity freshwater & 6.4 & 5.3 & n.a. & n.a. & 2.2 & 10.9 \\
\hline Resource depletion water & 6.1 & 29.6 & n.a. & 5.2 & 1.4 & 5.1 \\
\hline Resource depletion & 6.1 & 3.0 & n.a. & n.a. & n.a. & 6.9 \\
\hline
\end{tabular}

In bold the impact categories having the highest weight in each weighting set

Some of the methods considered do not include all the impact categories of ILCD; for these impact categories, we decided to assign a WF equal to zero. Excluding these impact categories, the higher variability among the four sets considered is shown in ozone depletion (where EDIP 2003 has a factor of 63 compared to values around 1 of the others) and water resource depletion (6.38 in WFsB compared, e.g., to 1 in WFsA and 0.65 in Tuomisto et al. 2012).

In general, weighting methods based on carrying capacity show higher variability of weights among impact categories, whereas weighting methods based on policy targets are much more balanced. This could have different explanations:

- The changes introduced by the policy targets have limited influence on the overall values of the indicators.

- The indicators have a limited capability of capturing the reduction in impacts induced by policies because they are biased toward some few elementary flows that dominate the entire impact category. In this case, if the policy targets address a different flow, the influence of the change will not modify significantly the final WF value. For instance, toxicity-related impact categories in ILCD are dominated by heavy metals, whereas most of the policy targets, derived from the results of impact assessment studies, focus on pesticides and biocidal substances.

- The inventory in 2010 is underestimating the values associated to the pollutants or resources targeted by policies.
- Policy targets act in many cases on few flows which are significantly contributing to many categories of impact (i.e., the impact categories are highly correlated; therefore, they vary in a similar way) as it is the case for combustion-related emissions.

- Environmental policy targets are based on an evaluation of the current situation (e.g., emission inventories in a given year) and take into account aspects like technical feasibility, political acceptance and economic costs, proportionality, etc., whereas methods based on carrying capacity often imply more stringent targets for some impact categories, sometimes set on longer time horizons than 2020 or 2030.

All of these characteristics might partially explain the results to different extent depending on the specificity of each impact category. It is also worthy to consider that in methods based on carrying capacity, not all the impact categories are covered and that policy-based methods include more impact categories. Therefore, the comparison between the weights associated to each impact category across weighting methods has to be interpreted with caution.

Figure 2 presents the results obtained applying WFsA, WFsB, an equal weight (1) for all the impact categories, and other weighting sets proposed in the literature, again using the EU energy mix dataset as an example. The WFs are applied to the characterization results (method: ILCD midpoint 1.06) of the process " $1 \mathrm{kWh}$ Electricity, medium voltage, production RER, at grid/RER U" from Ecoinvent v. 2.2 database, normalized using NFs 2010. 


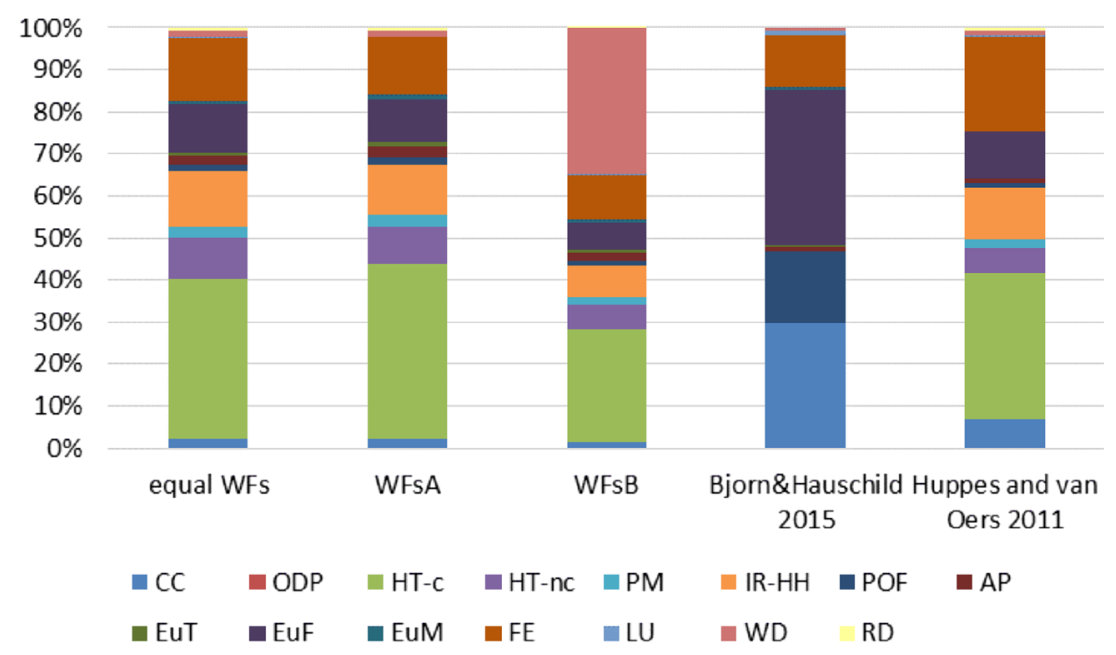

Fig. 2 Example of results obtained applying different weighting sets (equal WFs means that WFs are equal to 1 for all the impact categories and is taken as baseline reference). The WFs are applied to the characterization results (method: ILCD midpoint) of the process "1 kWh Electricity, medium voltage, production RER, at grid/RER U" from Ecoinvent v. 2.2 database, normalized using NFs 2010. CC climate

change, $O D P$ ozone depletion potential, $H T-c$ human toxicity-cancer, $H T$ $n c$ human toxicity-non-cancer, $P M$ particulate matter, $I R-H H$ ionizing radiation, $P O F$ photochemical ozone formation, $A P$ acidification potential, EuT eutrophication, terrestrial, EuF eutrophication, freshwater, $E u M$ eutrophication, marine, $F E$ freshwater ecotoxicity, $L U$ land use, $W D$ water depletion, $R D$ resources depletion

Results for the other four weighting sets considered are quite consistent: even if there are some differences in the relative importance of the impact categories, the most important ones (human toxicity - cancer effects, freshwater ecotoxicity, and freshwater eutrophication) are the same among the four sets, with the only exception of water depletion, contributing the most in WFsB. Results obtained applying the method by Bjorn and Hauschild (2015) are quite different from the others. The final single score is dominated by freshwater eutrophication, climate change, and photochemical ozone formation. However, when interpreting the results, it has to be considered that this method does not provide WFs for some of the ILCD impact categories, including toxicity-related ones.

These results, if compared to the result of normalization, presented in Fig. 1, suggest that the normalization step may play a more relevant role than the weighting step, influencing more the single aggregated score of the process under investigation. This is confirmed also when only the impact categories for which a WF is available in all the sets discussed and compared before are considered (Figs. S3 and S4, Electronic Supplementary Material).

\section{Conclusions}

The resulting sets present strengths and limitations. The translation of policy targets into quantitative modifications to the baseline inventories $(2010,2005,1990)$, in order to derive TFs for 2020, appeared to be not a straightforward task, due to several reasons discussed below.

Indeed, the review of policy documents helped to identify a wide range of targets but still not covers completely all the

impact categories considered in the LCIA phase. Moreover, it is not easy to identify non-binding targets - especially if they are not set within a policy document—-so at the moment, the number of non-binding targets applied is quite limited.

Not all the policy targets are expressed in quantitative terms or can be translated into quantitative reductions/modifications of the elementary flows in the existing baseline inventories. In some cases, the target is posed to a year different from 2020, so the target for 2020 needs to be re-scaled through linear interpolation (e.g., when the policy target refers to a period in time beyond 2020).

In addition, the underlying methodology used to develop the inventory 2010, which was used as a basis for the calculation, can pose some limitations to the present exercise, where the NFs and WFs are supposed to be applied to the results of process-based LCAs, based on inventories developed in a different way. Firstly, no delayed emissions are taken into account in the inventory 2010. Therefore, even if we respect the target in terms of actual emissions in the target year, in 2020, we may have the occurrence of emission due to delayed emission generated by end-of-life processes or the release of stored emissions (e.g., in wood-based products), the release of POPs, etc. In the same way, neither long-term emissions are included, i.e., not taken into account in 2020 .

Secondly, even if some of the targets identified are differentiated among EU countries (e.g., GHG reduction targets according to burden sharing approach), no spatialization was performed when applying these targets to 2010 (or 1990/2005) inventory. Therefore, the effect of spatial differentiation is not taken into account in the WFs (which are the same for all the EU). 
Thirdly, some of the targets refer to issues that are currently not covered by LCIA methods, i.e., not included in the baseline inventory. An example is the target for indoor air quality posed by EC 2004. The regulation posed non-binding ceilings to ambient concentration of arsenic, cadmium, nickel, and benzo(a)pyrene by 2013. At present, indoor emissions and concentrations are not covered by any of the existing LCIA methods, even if there are some proposals of methods to account for it (e.g., Hellweg et al. 2009). The same applies to biotic resources, noise, and erosion, which are not covered by the ILCD methods used for this study (EC-JRC 2011).

Moreover, the use of the normalization step in LCA as an approach through which to compare different impacts might reveal some limitations as well, as discussed by Heijungs et al. (2007). For instance, the wrong quantification of the NFs, either as underestimation or overestimation, might result in a misleading comparison among impact categories and further wrong prioritization. Also, policy targets NFs can be affected by the same limitation in case that they are calculated as relative reduction from the NFs observed in 2010. Factors such as the robustness of the underlying methodologies and datasets should hence be included in the process of prioritization among impact categories. In addition to that, the perspective adopted in the assessment of the normalization values (i.e., domestic vs. apparent consumption) might change substantially the results. This is important especially for targets on resources that focus on consumption (including embodied). Imports of metals in Europe, when expressed in mass, are eight times higher than domestic extraction (gold and copper are the main contributors to the total import) whereas import of energy carriers is twofold the extraction in EU. Other targets are on territorial scale, focusing on domestic emission reduction, and might be less affected by the inclusion of trade in the assessment.

Finally, it is worthy to mention that some DTT weighting methods such as Ecoindicator 95 (Goedkoop 1995) use damage WFs for DTT weights, i.e., calculate the weights as $W i=w_{i} * N_{i} / T_{i}$. On the contrary, the proposed method assumes that the target-based normalization references are determined at the same damage level; i.e., it is equally important to achieve the target values within each impact category in 2020. The authors are aware that policies related to different impacts are defined taking into consideration each single issue and not an overall picture of their potential effects; however, giving normative weights to the different DTTs is considered out of the scope of the present exercise.

Further development of the methodology, aimed at improving the effectiveness in supporting policies, can be the integration with other DTT approaches, which may refer not only to policy-based targets (like in the present study) but also to those based on the carrying capacity concept. As discussed before, some examples of DTT method referred to distance from planetary boundaries (Tuomisto et al. 2012) have already been proposed.
The proposed non-binding target set for water is based on an assumption of a carrying capacity of water systems, where the use of water below $20 \%$ of renewable water resources is considered as a sustainability threshold not to be trespassed. However, the definition of quantitative targets based on planetary boundaries can be particularly critical when dealing with some impact categories, especially in case of potential irreversibility of the damage, as it is for toxicity-related impact categories. In this case, a precautionary approach may suggest to define a target such as zero potentially affected fraction (PAF) to protect ecosystems and human health, which can pose strong challenges when need to be put into practice. Therefore, further research and discussion are needed on this topic with the aim of improving the environmental relevance of targets and related normalization and WFs to be applied in LCA practice.

Acknowledgments The work on weighting methods was partly financially supported by the Directorate General Environment (DG ENV) of the European Commission in the context of the Administrative Arrangement "Technical support for Environmental Footprinting, material efficiency in product policy and the European Platform on LCA" (No. 07.0307/ENV/2013/SI2.668694/A1).

Open Access This article is distributed under the terms of the Creative Commons Attribution 4.0 International License (http:// creativecommons.org/licenses/by/4.0/), which permits unrestricted use, distribution, and reproduction in any medium, provided you give appropriate credit to the original author(s) and the source, provide a link to the Creative Commons license, and indicate if changes were made.

\section{References}

Bare J, Gloria TH, Norris G (2006) Development of the method and U.S. normalization database for life cycle impact assessment and sustainability metrics. Environ Sci Technol 40(16):5108-5115

Bengtsson M, Steen B (2000) Weighting in LCA-approaches and applications. Environ Prog 19(2):101-109

Benini L, Mancini L, Sala S, Schau EM, Manfredi S, Pant R (2014a) Normalisation method and data for Environmental Footprints. Del.2 of the AA with DG ENV: № 070307/2012/ENV.C.1/635340

Benini L, Sala S, Manfredi S, Góralczyk M (2014b) Overall environmental impact (resource) indicators. Del. 3 of the AA with DGENV Scientific support for screening and development of potential resource efficiency and product-group indicators as well as targets for the reduction of the overall environmental impact of EU consumption

Bjørn A, Hauschild MZ (2015) Introducing carrying capacity-based normalisation in LCA: framework and development of references at midpoint level. Int J Life Cycle Assess 20(7):1005-1018

Dahlbo, H., Koskela, S., Pihkola, H., Nors, M., Federley, M., \& Seppälä, J. (2013) Comparison of different normalised LCIA results and their feasibility in communication. The International Journal of Life Cycle Assessment, 18(4), 850-860

European Commission (EC) (2004) Directive 2004/107/EC of 15 December 2004 relating to arsenic, cadmium, mercury, nickel and polycyclic aromatic hydrocarbons in ambient air 
European Commission (EC) (2009) Decision 406/2009/EC on the effort of Member States to reduce their greenhouse gas emissions to meet the Community's greenhouse gas emission reduction commitments up to 2020

EC (2011) Roadmap to a Resource Efficient Europe. COM(2011) 571 final

EC (2013) Commission Recommendation of 9 April 2013 on the use of common methods to measure and communicate the life cycle environmental performance of products and organisations. ANNEX II : product environmental footprint (PEF) guide. European Commission

European Commission - Joint Research Centre (EC-JRC) (2011) International Reference Life Cycle Data System (ILCD) Handbook-recommendations for life cycle assessment in the European context - based on existing environmental impact assessment models and factors. ISBN 978-92-79-17451-3, doi: 10.278/ 33030. EC-JRC. Publications Office of the European Union, Luxembourg

EC - JRC (2012a) Life cycle indicators framework: development of life cycle based macro-level monitoring indicators for resources, products and waste for the EU-27. European Commission, Joint Research Centre, Institute for Environment and Sustainability

EC - JRC (2012b) Life cycle indicators for resources: development of life cycle based macro-level monitoring indicators for resources, products and waste for the EU-27. European Commission, Joint Research Centre, Institute for Environment and Sustainability

European Council (EUCO) (2014) Conclusions of the European Council on 24 October 2014, EUCO 169/14

Finnveden G, Hofstetter P, Bare J, Basson L, Ciroth A, Mettier T, Seppälä J, Johansson J, Norris G, Volkwein S (2002) Normalisation, grouping, and weighting in life cycle impact assessment. In: Udo de Haes HA et al. (ed) Life cycle impact assessment: striving towards best practice. Society of Environmental Toxicology and Chemistry (SETAC), Pensacola

Finnveden G, Hauschild MZ, Ekvall T, Guinee J, Heijungs R, Hellweg S, Koheler A, Pennington D, Suh S (2009) Recent developments in life cycle assessment. J Environ Manag 91:1-21

Frischknecht R, Büsser Knöpfel S (2013) Swiss Eco-Factors 2013 according to the Ecological Scarcity Method. Methodological fundamentals and their application in Switzerland. Environmental studies no. 1330. Federal Office for the Environment, Bern, $254 \mathrm{pp}$

Frischknecht R, Steiner R, Jungbluth N (2008) Ökobilanzen: Methode der ökologischen Knappheit - Ökofaktoren 2006. Methode für die Wirkungsabschätzung in Ökobilanzen. Öbu SR 28/2008. Öbu, Zürich, Switserland http://www.oebu.ch/oebu/downloads/ oekofaktoren_sr28.pdf

Galatola M, Pant R (2014) Reply to the editorial "Product environmental footprint-breakthrough or breakdown for policy implementation of life cycle assessment?" written by Prof. Finkbeiner (Int J Life Cycle Assess 19(2):266-271). Int J Life Cycle Assess 19(6):1356-1360

Goedkoop M (1995) The Eco-Indicator 95. RIVM Report 9523. Bilthofen, 1995

Guinée JB, Gorrée M, Heijungs R, Huppes G, Kleijn R, de Koning A, van Oers L, Wegener Sleeswijk A, Suh S, Udo de Haes HA, de Bruijn H, van Duin R, Huijbregts MAJ (2002) Handbook on life cycle assessment. Operational guide to the ISO standards. I: LCA in perspective. IIa: guide. IIb: operational annex. III: scientific background. Kluwer Academic Publishers, Dordrecht, 692 pp ISBN 1-4020-0228-9, $\mathrm{cml}$.leiden.edu/research/industrialecology/researchprojects/finished/new-dutch-lca-guide.html

Hauschild M, Potting J (2003) Spatial differentiation in life cycle impact assessment - the EDIP2003 methodology. Institute for Product Development Technical University of Denmark

Hauschild M, Wenzel H (1998) Environmental assessment of products. Vol. 2 Scientific background. Chapman \& Hall, United Kingdom/ Kluwer Academic Publishers, Hingham, MA, USA. pp 565
Heijungs R (2008) The weighting step in life cycle impact assessment. Three explorations at the midpoint and endpoint level. Weighting with damage costs. CML, Leiden University, Netherlands

Heijungs R, Guinée J, Kleijn R, Rovers V (2007) Bias in normalization: causes, consequences, detection and remedies. Int J Life Cycle Assess 12(4):211-216

Hellweg S, Demou E, Bruzzi R, Meijer A, Rosenbaum RK, Huijbregts MA, McKone TE (2009) Integrating human indoor air pollutant exposure within life cycle impact assessment. Environ Sci Technol 43(6):1670-1679

Huppes G, van Oers L (2011) Background review of existing weighting approaches in life cycle impact assessment (LCIA). JRC Scientific and Technical Reports, Luxembourg: Publications Office of the European Union, ISBN 978-92-79-21751-7, ISSN 1831-9424. http://bookshop.europa.eu/is-bin/INTERSHOP.enfinity/WFS/EUBookshop-Site/en_GB/-/EUR/ViewPublication-Start? PublicationKey $=$ LBNĀ24997

Huppes G, van Oers L, Pretato U, Pennington DW (2012) Weighting environmental effects: analytic survey with operational evaluation methods and a meta-method. Int J Life Cycle Assess 17(7):876-891

ISO (2006) ISO 14040 Environmental management-life cycle assessment- principles and framework. Geneva, Switzerland

Lin M, Zhang S, Chen Y (2005) Distance-to-target weighting in life cycle impact assessment based on Chinese Environmental Policy for the period 1995-2005. Int J Life Cycle Assess 10(6):393-398

Mancini L, Benini L, Sala S (2015) Resource footprint of Europe: complementarity of material flow analysis and life cycle assessment for policy support. Environ Sci Policy 54:367-376

Myllyviita T, Holma A, Antikainen R, Lähtinen K, Leskinen P (2012) Assessing environmental impacts of biomass production chainsapplication of life cycle assessment (LCA) and multi-criteria decision analysis (MCDA). J Clean Prod 29:238-245

Myllyviita T, Leskinen P, Seppälä J (2014) Impact of normalisation, elicitation technique and background information on panel weighting results in life cycle assessment. Int J Life Cycle Assess 19(2):377386

Pennington DW, Potting J, Finnveden G, Lindeijer E, Jolliet O, Rydberg T, Rebitzer G (2004) Life cycle assessment part 2: current impact assessment practice. Environ Int 30:721-39

Pizzol M, Weidema B, Brandão M, Osset P (2015) Monetary valuation in life cycle assessment: a review. J Clean Prod 86:170-179

Powell JC, Pearce DW, Craighill AL (1997) Approaches to valuation in LCA impact assessment. Int J Life Cycle Assess 2(3):163-169

Rockström J, Steffen W, Noone K, Persson A, Chapin FS, Lambin E, Lenton TM, Scheffer M, Folke C, Schellnhuber HJ, Nykvist B, de Wit CA, Hughes T, van der Leeuw S, Rodhe H, Sorlin S, Snyder PK, Costanza R, Svedin U, Falkenmark M, Karlberg L, Corell RW, Fabry VJ, Hansen J, Walker B, Liverman D, Richardson K, Crutzen P, Foley J (2009) Planetary boundaries: exploring the safe operating space for humanity. Ecol Soc 14(2):32

Sala S, Benini L, Mancini L, Ponsioen T, Laurent A, van Zelm R, Stam G, Goralczyk M, Pant R (2014) Methodology for building LCAcompliant national inventories of emissions and resource extraction. Background methodology for supporting calculation of product environmental footprint normalisation factors and resource efficiency indicators for EU. JRC science and policy report

Sala S, Benini L, Mancini L, Pant R (2015) Integrated assessment of environmental impact of Europe in 2010: data sources and extrapolation strategies for calculating normalisation factors. Int $\mathrm{J}$ Life Cycle Assess 20(11):1568-1585

Seppälä J, Hämäläinen RP (2001) On the meaning of the distance-totarget weighting method and normalisation in life cycle impact assessment. Int J Life Cycle Assess 6(4):211-218

Soares SR, Toffoletto L, Deschênes L (2006) Development of weighting factors in the context of LCIA. J Clean Prod 14(6):649-660 
Strauss K, Brent A, Hietkamp S (2006) Characterisation and normalisation factors for life cycle impact assessment mined abiotic resources categories in South Africa: the manufacturing of catalytic converter exhaust systems as a case study. Int J Life Cycle Assess 11(3):162-171

Tuomisto HL, Hodge ID, Riordan P, Macdonald DW (2012) Exploring a safe operating approach to weighting in life cycle impact assessment - a case study of organic, conventional and integrated farming systems. J Clean Prod 37:147-153

Vandecasteele I, Bianchi A, Batista e Silva F, Lavalle C, Batelaan O (2014) Mapping current and future European public water withdrawals and consumption. Hydrol Earth Syst Sci 18:407-416
Wang H, Hou P, Zhang H, Weng D (2011) A novel weighting method in LCIA and its application in Chinese policy context. In: Towards life cycle sustainability management. Springer Netherlands, pp 65-72

Wegener-Sleeswijk A, Van Oers LFCM, Guinée JB, Struijs J, Huijbregts MAJ (2008) Normalisation in product life cycle assessment: an LCA of the global and European economic systems in the year 2000. Sci Total Environ 390:227-40

Wenzel H, Hauschild MZ, Alting L (1997) Environmental assessment of products. Vol.1. 544 pp. Chapman \& Hall, United Kingdom, Kluwer Academic Publishers, Hingham, MA. USA. ISBN 0412808005 